\title{
Density Functional Theoretical Study on the N-H Bond Activation by Ir Pincer Complexes
}

\author{
Hyun Cho, Han Young Woo, ${ }^{\dagger}$ and Sungu Hwang ${ }^{\ddagger *}$ \\ Department of Nanomechatronics Engineering, Pusan National University, Miryang 627-706, Korea \\ ${ }^{\dagger}$ Department of Cogno-Mechatronics Engineering, Pusan National University, Miryang 627-706, Korea \\ $\$$ Department of Nanomedical Engineering, Pusan National University, Miryang 627-706, Korea \\ *E-mail:sungu@pusan.ac.kr \\ Received February 14, 2010, Accepted March 15, 2010
}

Key Words: DFT, Reductive elimination, N-H bond activation, $\operatorname{Ir}(\mathrm{III})$, Pincer ligand

The N-H bond activation reaction that was catalyzed with metal complexes has been the subject of many studies because of the prevalence of the nitrogen-containing compounds in pharmaceuticals and other fine chemicals. ${ }^{1-2}$ Ir catalysts that are supported by pincer or aliphatic ligands have been one of the most widely studied systems. For example, the insertion of an Ir complex into an N-H bond in ammonia forms a stable amido hydride complex in solution at room temperature. ${ }^{2}$

Recently, a report showed that Ir complexes supported by silyl pincer ligands undergo an N-H bond oxidative addition for both ammonia and aniline, which forms isolable [Cy-PSiP] $\operatorname{Ir}(\mathrm{H})$ $(\mathrm{NHR})\left(\mathrm{R}=\mathrm{H}\right.$, or aryl; $\left.[\mathrm{Cy}-\mathrm{PSiP}]=\left[\kappa^{3}-\left(2-\mathrm{Cy}_{2} \mathrm{PC}_{6} \mathrm{H}_{4}\right)_{2} \mathrm{SiMe}\right]^{-}\right)$ complexes. $^{1}$

One of the key issues in this iridium chemistry is the relative stability between the amido hydride complex and the amine complex. ${ }^{2}$ An appropriate pincer ligand can be used to control

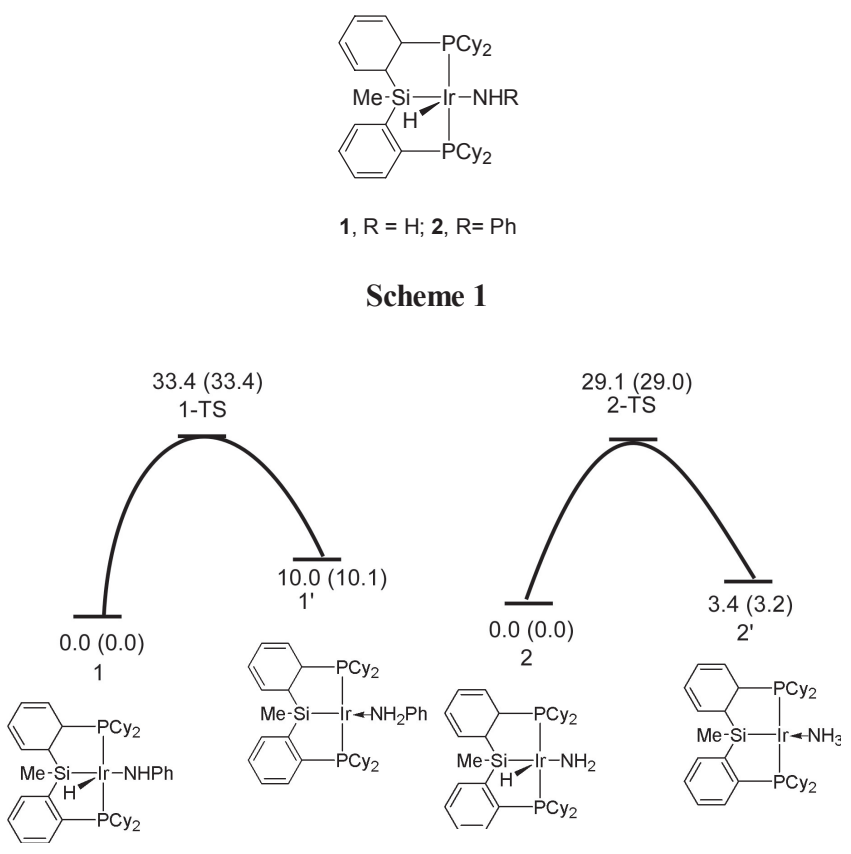

Figure 1. Relative Gibbs free energy diagram from the B3LYP/ LACVP** calculations, where TS denotes the transition states, and ' denotes the amine complexes (The values in parentheses are the gasphase data). the thermodynamics and kinetics of the chemical transformation between the two types of complexes.

In this study the density functional theoretical (DFT) studies were conducted in order to determine the Gibbs energy of the activation of $\mathrm{N}-\mathrm{H}$ bond coupling in $\mathbf{1}$ and the relative stability between the amido hydride complex and the amine complex. Additionally, the characteristics of this reaction were compared to other related compounds.

Figure 1 shows the Gibbs free energy diagrams for $\mathbf{1}$ and $\mathbf{2}$ and Figure 2 shows the optimized structures that were obtained (a) 1

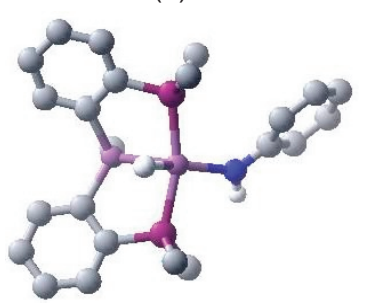

(c) 1-TS

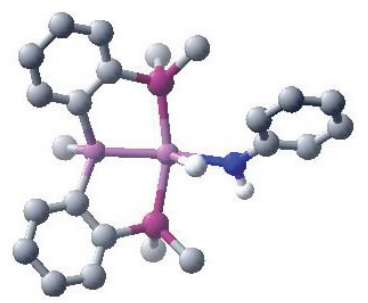

(e) $1^{\prime}$

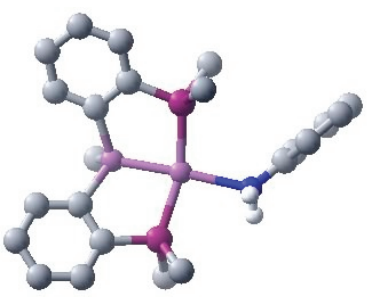

(b) 2

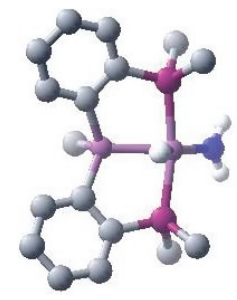

(d) 2-TS

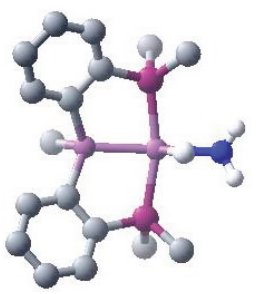

(f) 2'

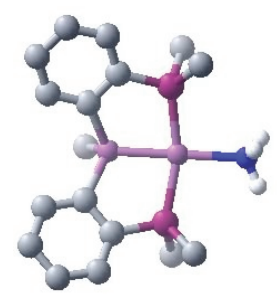

Figure 2. Optimized structures of the minima and transition states from the B3LYP/LACVP** calculations. The hydrogen atoms, except the methyl hydrogens and hydride that was attached to Ir, were not shown for clarity. TS represents the transition states, and ' indicates the amine complexes. 
from the B3LYP/LACVP** calculations. The gas-phase thermodynamic quantities were also included for comparison purposes. The Gibbs activation energy, $\Delta G^{\ddagger}$, was $33.4 \mathrm{kcal} / \mathrm{mol}$ for 1 and $29.0 \mathrm{kcal} / \mathrm{mol}$ for $\mathbf{2}$ in the gas phase at $298 \mathrm{~K}$. The cyclohexane solvation energy correction marginally changed the numerical results for the $\Delta G^{\ddagger}$ with values of $33.4 \mathrm{kcal} / \mathrm{mol}$ for 1 and 29.1 $\mathrm{kcal} / \mathrm{mol}$ for 2 , as expected from the nonpolar nature of the solvent. The Gibbs energy of the reaction, $\Delta G_{\text {reaction, was }} 10.1$ $\mathrm{kcal} / \mathrm{mol}$ in the gas phase and $10.0 \mathrm{kcal} / \mathrm{mol}$ in the solution, which indicated that amido hydride was more stable than amino group for $\mathbf{1}$. For 2 , the $\Delta G_{\text {reaction }}$ was $3.2 \mathrm{kcal} / \mathrm{mol}$ in the gas phase and $3.4 \mathrm{kcal} / \mathrm{mol}$ in the solution, which also indicated that amido hydride prevailed. Both of these values were in good agreement with the NMR and other experimental results. ${ }^{1}$

The geometries of the reactants, the transition states, and the amine-complexes were examined in order to understand the energy barrier of the N-H coupling and the relative stability of the amino hydride complex compared to the amine complex. Figure 2 shows the optimized structures from the B3LYP/ LACVP** calculations.

The Ir complexes, $\mathbf{1}$ and $\mathbf{2}$, exhibited distorted square pyramidal geometries with a nearly planar coordination around Ir. The Ir-N bond length in $\mathbf{1}$ was $2.07 \AA$, which was comparable to the values that were found in the X-ray structure ${ }^{1}$ and the related pincer Ir(III) complexes. ${ }^{3}$ The Ir-N bond length in $\mathbf{2}$ was $2.01 \AA$, which was also comparable to the value that was found in the related pincer $\mathrm{Ir}(\mathrm{III})$ amido hydride complexes. ${ }^{2}$

In 1-TS, the Ir-H bond length was elongated to $1.64 \AA$, and the Ir-N bond was stretched to $2.23 \AA$, resulting in a H-N distance of $1.50 \AA$ and a H-Ir-N angle of $42.2^{\circ}$, compared to $155.6^{\circ}$ in 1. In 2-TS, the Ir-H bond length was elongated to $1.62 \AA$, and the Ir-N bond was $2.18 \AA$, resulting in a H-N distance of $1.55 \AA$ and a H-Ir-N angle of $45.4^{\circ}$ compared to $152.3^{\circ}$ in 2 .

In 1', the Ir-N bond was lengthened to $2.37 \AA$. On the other hand, the H-N distance was shortened to $1.02 \AA$. In 2', the Ir-N bond was stretched to $2.31 \AA$, and the $\mathrm{H}-\mathrm{N}$ distance was shortened to $1.02 \AA$.

Additional calculations were performed in order to determine the dependence on the ligand. The silicon atoms in $\mathbf{1}$ and $\mathbf{2}$ were replaced with carbon (See Scheme 2). In the gas phase, the Gibbs activation energy for the N-H coupling was reduced to $24.5 \mathrm{kcal} / \mathrm{mol}$ in 3 and $24.0 \mathrm{kcal} / \mathrm{mol}$ in 4 . The solvation energy correction adjusted the $\Delta G^{\ddagger}$ values to $27.4 \mathrm{kcal} / \mathrm{mol}$ for the 3 and $23.9 \mathrm{kcal} / \mathrm{mol}$ for 4 . The Gibbs energy of the reaction, $\Delta G_{\text {reaction, was }} 7.2 \mathrm{kcal} / \mathrm{mol}$ in the gas phase and $4.6 \mathrm{kcal} / \mathrm{mol}$ in the solution, which indicated that the amido hydride was more stable than the amino group for $\mathbf{3}$. For $\mathbf{4}$, the $\Delta G_{\text {reaction }}$ was 1.1 $\mathrm{kcal} / \mathrm{mol}$ in the gas phase and $1.4 \mathrm{kcal} / \mathrm{mol}$ in the solution, which also indicated that amido hydride was only marginally better.

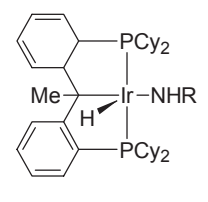

3, $\mathrm{R}=\mathrm{Ph} ; \mathbf{4}, \mathrm{R}=\mathrm{H}$

Scheme 2
Both the energy barrier of the N-H coupling reaction and the Gibbs energy of the reaction were reduced as the net result of the substitution (Si to C). Although many factors control the kinetics and the thermodynamics of the coupling reaction, the relative stability can be affected by the electron density at the metal center. ${ }^{2}$ The strongly electron donating ligand [Cy-PSiP] favored the amido hydride complex over the ammonia complex. ${ }^{4}$ The coordination of ammonia would transfer considerable amount of electron density to the already electron-rich metalcenter in the presence of other electron donating ligand. ${ }^{2}$

In summary, the DFT calculations were performed for the $\mathrm{N}-\mathrm{H}$ coupling reaction of the pincer type $\mathrm{Ir}$ (III) complexes. The transition states were successfully located, and the thermodynamic and kinetic results were consistent with the existing experimental data and previous computational results for the same types of complexes. ${ }^{1}$ We showed that the [CyPSiP] ligand led to a stable amido hydride complex.

\section{Computational Details}

The geometry was optimized at the B3LYP/LACVP** level of the theory using the Jaguar v5.5 suite. ${ }^{5}$ The stability of all of the minima, including the intermediates and the transition states (TSs), was evaluated by calculating the standard Gibbs energy of each species at $298.15 \mathrm{~K}$ using the following equation.

$$
\Delta G=E_{0}+\mathrm{ZPE}+\Delta \Delta G_{0 \rightarrow 298}
$$

The total energy of the molecule at $0 \mathrm{~K}\left(E_{0}\right)$ was calculated at the optimal geometry from the B3LYP/LACVP** computational level. The zero-point energy (ZPE) and the change in the Gibbs free energy from $0 \mathrm{~K}$ to $298.15 \mathrm{~K}\left(\Delta \Delta G_{0 \rightarrow 298}\right)$ were evaluated at the same level of the theory. The thermodynamic quantities were evaluated according to the rigid-rotor harmonic oscillator approximation using the computed harmonic frequencies from the B3LYP/LACVP** calculations. The local minima and the TSs were identified using the harmonic frequency analysis from the analytical Hessian calculations. The reaction paths were traced from the TSs using the intrinsic reaction coordinate (IRC) method in order to confirm that the reactants and products were correct. ${ }^{6,7}$ The Poison-Boltzmann (PB) continuum model ${ }^{8,9}$ was used in order to describe the solvent (cyclohexane) at the B3LYP/LACVP** level. The solvent probe radius was $2.777 \AA$, and the solvent dielectric constant was 2.023 . The solvation energy corrections were calculated for the optimized gas phase geometries at the B3LYP/LACVP** level. The cyclohexyl groups that were attached to the phosphorus atoms in all of the complexes were replaced with the methyl groups in order to reduce the computational burden.

Acknowledgments. This work was supported by a Pusan National University Research Grant.

\section{References}

1. Morgan, E.; MacLean, D. F.; McDonald, R.; Turculet, L. J. Am. Chem. Soc. 2009, 131, 14234. 
2. Zhao, J.; Goldman, A. S.; Hartwig, J. F. Science 2005, 307, 1080.

3. Kanzelberger, M.; Zhang, X.; Emge, T. J.; Goldman, A. S.; Zhao, J.; Incarvito, C.; Hartwig, J. F. J. Am. Chem. Soc. 2003, 125, 13644.

4. MacLean, D. F.; McDonald, R.; Ferguson, M. J.; Caddell, A. J.; Turculet, L. Chem. Comm. 2008, 5148.

5. Jaguar v5.5; Schrodinger Inc.: Portland, Oregon, 2003.

6. Gonzalez, C.; Schlegel, H. B. J. Chem. Phys. 1989, 90, 2154.
7. Gonzalez, C.; Schlegel, H. B. J. Phys. Chem. 1990, 94, 5523.

8. Marten, B.; Kim, K.; Cortis, C.; Friesner, R. A.; Murphy, R. B.; Ringnalda, M. N.; Sitkoff, D.; Honig, B. J. Phys. Chem. 1996, $100,11775$.

9. Tannor, D. J.; Marten, B.; Murphy, R.; Friesner, R. A.; Sitkoff, D.; Nicholls, A.; Ringnalda, M. N.; Goddard, W. A., III.; Honig, B. J. Am. Chem. Soc. 1994, 116, 11875. 